\title{
Nonintubated Videothoracoscopic Operations in Thoracic Oncology
}

Tommaso C Mineo* and Federico Tacconi

Thoracic Surgery Division, Tor Vergata University, Italy

*Corresponding author: Dr. Tommaso C Mineo, Thoracic Surgery Division, Tor Vergata University Floor 7th, Viale Oxford 81,00133 , Rome, Italy, Tel: 003906 20902880; Fax: 003906 20902881; E-mail: mineo@uniroma2.it

Received date: 25 February 2014, Accepted date: 20 March 2014, Published date: 30 March 2014

Copyright: ( 2014 Mineo TC, et al. This is an open-access article distributed under the terms of the Creative Commons Attribution License, which permits unrestricted use, distribution, and reproduction in any medium, provided the original author(s) and source are credited.

\begin{abstract}
Background: Despite general anesthesia with one-lung ventilation represents the standard to perform thoracic surgery operations, there is an increasing interest toward alternative methods, such as the use of local or neuroaxial analgesia alone in fully alert or mildly sedated patients. These can be applied to perform a series of videothoracoscopic procedures.
\end{abstract}

Material and Methods: We reviewed our own institutional experience with this kind of surgery, as well as the most relevant literature findings available on this topic at the usual search websites (PubMed, Scopus, EMBASE). We focused on more recent advances regarding indications, expected advantages, possible pitfalls and implications for future research.

Results: Such an operative modality can be safely and successfully adopted to manage a series of common malignant and non-malignant diseases. In thoracic oncology, it is mainly employed to treat malignant pleural effusion, to remove of pulmonary lesions of any origin, and to perform mediastinal biopsies. Furthermore, even complex procedures such anatomic lung resections and thymectomy are now being performed in this way. When taking into the account just intermediate to major surgeries, reported conversion rates to general anesthesia range between 2.8 and $9 \%$. Despite the lack of randomized controlled trial, there is a general perception that non-intubated videothoracoscopic operation may translate into a lower morbidity rate, better hematosis, and preserved perioperative immunosurveillance. No sufficient data is available as far as long-term outcomes are concerned.

Conclusions: Non-intubated videthoracoscopic operations may be as effective as the equivalent procedures performed with general anesthesia, while providing advantages in terms of cost and postoperative morbidity. This surgical practice should thus be included in the armamentarium of modern era thoracic surgeons, and appropriately designed studies should be undertaken to better define its merits and limitations.

Keywords: Regional anesthesia; VATS; non-small cell lung cancer; lung resection; pulmonary metastasecomy; mediastinal masses; pleural effusion

\section{Introduction}

With the advent of the patient-centered health care concept, there is an increasing attention to minimize at most the global invasiveness of surgical performances, while maintaining an unaltered level of safety and effectiveness. In recent years, this need has driven an outstanding development of minimally-invasive operative modalities, which are now the accepted standard to perform a broad spectrum of thoracic operations. Meanwhile, the advances in anesthesiology practice have given a further contribution to the improvement of postoperative outcomes, particularly thanks to the widespread diffusion of regional and neuraxial techniques. The latter are usually adopted in combination with general anesthesia, whit the purpose of achieving better postoperative pain control, attenuated response to surgical stress, and reduced dosage of intravenous or volatile anesthetic drugs. Yet, regional anesthesia can be also used as a standalone tool to carry out thoracic operations in spontaneously ventilated patients, thus obviating the need of general anesthesia and orotracheal intubation [1-5]. This operative modality, which has been also named as "awake" or "non-intubated" thoracic surgery, is now gaining increasing acceptance is some institutions, even though there is no definitive consensus in terms of indications, possible advantages, and pitfalls (Table 1). In this article, we review the basic concepts of this kind of surgical practice, with special focus on its applicability to the specific subset of oncology diseases (Non-Intubated Thoracic Oncology Surgery, NITOS).

\begin{tabular}{|l|}
\hline Main PROS \\
\hline Avoidance of GA and OLV related adverse effect \\
\hline Reduced postoperative morbidity/shorter hospitalization \\
\hline Improved quality of recovery \\
\hline Time and cost saving advantages \\
\hline Non-inferior efficacy versus standard approaches \\
\hline $\begin{array}{l}\text { Possible anticancer activity ( } \downarrow \text { perioperative cortisol release } \rightarrow \text { preserved NK } \\
\text { activity) }\end{array}$ \\
\hline Main CONS \\
\hline TEA-related side effects to be taken into the account when used \\
\hline Lack of evidence-based support \\
\hline
\end{tabular}


More difficult surgical technique $\rightarrow$ specific training mandatory

Patient safety questionable

Table I: Hypothesized Pros and Cons of NITOS operations. GA: general anesthesia; NK: Natural-killer; OLV: One-lung ventilation; TEA: Thoracic Epidural Anesthesia.

\section{Material and Methods}

\section{General Principles}

The basic idea of NITOS is that a global drop of perioperative morbidity rate could be obtained by avoiding a series of injurious effect and complications related to general anesthesia and One-Lung Ventilation (OLV). This consideration mainly applies to patients with composite comorbidity status, who are more prone to develop postoperative adverse events.

It is well known that OLV in itself, regardless of surgical manipulations, may induce inflammatory changes at the level of small airways and lung parenchyma, through diverse mechanisms [6-22]. The latter include elevated positive pressure (barotrauma), alveolar overdistension (volutrauma) $[8,10]$, repetitive collapse-reopening cycles (atelettrauma) [10], low oxygen tension, and the so-called reventilation injury $[13,14,22]$. All these factors are responsible for oxidative stress $[16,19,20,21]$ and excess recruitment of inflammatory cells, with subsequent activation of cytokine network and establishment of an inflamed microenvironment $[8,11-13,15]$. These compartmental changes, which can involve both the dependent and non-dependent (operated) lung, configure a condition known as "Ventilator-Associated Lung Injury" (VALI). The latter leads, in turn, to interstitial edema $[12,14,16]$, loss of surfactant $[11,12]$, ventilationto-perfusion mismatch, and decreased lung compliance $[11,12]$. These effects occur in a time-dependent manner, as they increase remarkably after 1-hour of OLV [20]. In most instances, VALI can remain clinically silent, or be responsible for just transient and mild respiratory impairment. In patients with preexisting lung diseases, however, VALI may evolve to frank acute lung injury according to the so-called double-hit paradigm. This severe complication can occur in nearly $4 \%$ of major lung resections $[17,18]$ and can carry a mortality rate as high as $25 \%$. Excess fluid administration [18], pain, phlegm retention, and atelectasis are common factor which can participate to worsen this clinical scenario.

Systemic effects of VALI can also be seen, and are likely mediated by spillover of proinflammatory cytokines to the blood circulation [23]. They include liver injury [23], natural-killer cells (NK) impairment [24], and cardiac arrhythmias [25]. Despite these complications are usually self-limiting and well treatable, they can trigger potentially life-threatening deterioration in more fragile patients.

Other common adverse effects of general anesthesia in thoracic patients include acute kidney injury, diaphragmatic failure, postoperative cognitive impairment, and tracheobronchial rupture. Despite the latter has been estimated to occur with a relatively low rate $(1 / 20.000)$, it may be life-threatening in more than $20 \%$ of istances [26].

\section{Surgery, anesthesia and cancer progression}

Another matter of investigation is as to whether the employ of locoregional techniques, alone or in combination with general anesthesia, can modify the biological behavior of cancer cells, thus affecting postoperative outcomes. In this regard, it is well known that both surgical manipulations and general anesthesia may interfere with tumor growth through diverse mechanisms. First, surgical stress and postoperative pain themselves may accelerate escape of occult tumor foci from their dormancy condition, thus promoting both local and distant recurrences $[27,28]$. This association has been proven to occur in both human and animal settings, and is mainly attributed to postsurgical suppression of immunosurveillance against tumor cells. The mechanisms undelying postoperative immune suppression, which mostly involves NK and T-helper cells, are quite complex and, probably, not fully understood. However, existing data strongly support the hypothesis of a transient dysregulation of the endocrine system leading to a dysproportionate release of endogenous steroids, alongside with a deranged cytokine production. Furthermore, the same factors may also directly promote tumor growth. In particular, circulating catecholamines, which also increase after surgery, may themselves promote tumor cell replication, migration, and expression of angiogenetic factors via an interaction with $\beta-1$ and $\beta-2$ receptors on tumor cell surface.

Some factors related to general anesthesia itself are also believed to interfere with postsurgical tumor progression $[27,28]$. For example, opioids seems to have a role in immune suppression, even though existing data in this regard are quite controversial. The $\alpha-2$ agonist dexmedetodimine, which is being increasingly used to induce deep sedation in both surgical and ICU settings, has been shown to enhance proliferation of breast cancer cells which express the adrenergic receptor on theirs surface [29]. Other anesthetic agents that have been shown to significantly impair NK cells activity are ketamine, thiopental, and halothane [28]. Moreover, some of these are also capable to directly promote cancer growth, mainly via the induction of the so-called Hypoxia Inducible Factors (HIF), which are responsible for cancer cell survival within an unfavorable microenvironment. On contrary, propofol seems to express some anticancer activity, which has been attributed to its antiinflammatory properties, better control of surgical stress response, preservation of NK function and, again, suppression of the HIFs [28]. This is one of the reasons why propofol, alone or in combination with short-acting opioids such sufentanyl or remifentanyl, are now generally preferred to perform NITOS procedures. Mechanical ventilation and, in particular, OLV could also contribute to immunesurveillance impariment, because of its ability to promote local and systemic proinflammatory cytokine release. In this regard, Tonnesen and coworkers have found that, in patients undergoing elective thoracic surgeries, OLV in itself can reduce NK activity regardless of surgical manipulations [24].

Regional anesthesia reduces stress response to surgery by blocking afferent neural transmission, thus resulting into diminished cortisol release and attenuated systemic inflammation. Therefore, the protective role of regional anesthesia techniques against cancer progression has been thoroughly investigated. Despite the lack of prospective studies, robust evidence exists that the use epidural blockade in combination with general anesthesia can provide better oncologic outcomes in diverse cancer types. Unfortunately, much less data is available in respect to the use of local or regional anesthetics alone in NITOS. When putting these observations together, however, it appears conceivable that merging minimally-invasive surgical 
technique with methods to reduce stress response and general anesthesia-related trauma might contribute to reduced likelihood of perioperative tumor progression, possibly affecting long-term outcomes. We evaluated stress hormone release, systemic inflammation biomarkers, and lymphocyte response after videothoracoscopic operations performed in awake patients with just regional anesthesia, compared to those receiving equivalent procedures performed with general anesthesia and OLV [30,31]. In the former patients, we found an attenuated cortisol release, lower postoperative C-reactive protein peak, and preserved NK and total lymphocyte count. However, these two studies were made in low-risk individuals with benign diseases, so that it is unclear whether these findings can be extended to patients with thoracic malignancies, and whether they can translate into practical benefits in the short and long term. Another criticism is that, in both these studies, epidural anesthesia was used only in the study group, a factor which could have contributed to the the observed results more than the avoidance of OLV did. To our knowledge, no other study has addressed these topics, and more robust evidence is needed to draw clearer conclusions in this regard.

\section{Indications}

NITOS operations can be indicated to perform minor to intermediate procedures in patients unfit for general anesthesia, even though healthy patients may be considered as well. So far, however, no definitive recommendation exists. In our institution, we base the decision making process on the Thoracoscore risk calculator. This simple instrument, which is available online at the Societe' Francaise de Anesthesie and Reanimation website (www.sfar.org), allows to reliably predict the risk of deadly complications after thoracic surgery procedures according to a series of parameters, including age, dyspnea, American Society of Anesthesiology, performance status $\geq 3$, and composite comorbidity status. We have set a predicted risk of $2.3 \%$ as an acceptable threshold to consider NITOS as the elective approach whenever technically feasible. Major contraindications to NITOS are detailed in table 2, and mainly include conditions rendering the nonintubated procedure unsafe, oncologically unsound, or unfeasible at all. A summary of procedures we usually carry out through NITOS at our institution is provided in table 3 , which also shows some changes in surgical practice occurred within the years.

Table II: Major contraindications to NITOS.

Technically demanding or oncologically inadequate procedure

Known allergy to local anesthetics

High risk for intraoperative seizure (brain metastases)

Patient "not keen" to undergo surgery with conscious sedation

Impaired patient ability to cooperate

Past medical history of ipsilateral pleurisy, previous surgery or radiation therapy

Medium to severe obesity $(\mathrm{BMI}>35)$

Central hypoventilation syndrome

Hypercarbia $(\mathrm{PaO} 2>55 \mathrm{mmHg})$

Validated non-surgical options available

Spine deformities (if TEA to be used)
INR > 1.5 or current antiplatelets therapy

Table III: NITOS procedures at our institution: changes within years. GA: General Anesthesia; PROC: Procedure; NA: Not Applicable. * Total: represents the total number of NITOS operations. ${ }^{\star *}$ : Ratio of total procedures performed with NITOS to total equivalent procedures performed with general anesthesia. ${ }^{* * *}$ : Ratio of total NITOS procedures performed with uniportal access to total NITOS procedures performed with multiportal thoracoscopic access.

\begin{tabular}{|l|l|l|l|l|l|l|}
\hline PROC & \multicolumn{3}{|c|}{ 2002-2007 } & \multicolumn{3}{c|}{ 2007-2014 } \\
\hline & Total $^{*}$ & $\begin{array}{l}\text { NITOS } \\
\text { vs. GA } \\
* *\end{array}$ & $\begin{array}{l}\text { Uniportal } \\
\text { vs. } \\
\text { multiportal } \\
* \star \star\end{array}$ & Total* $^{*}$ & $\begin{array}{l}\text { NITOS } \\
\text { vs. GA } \\
* *\end{array}$ & $\begin{array}{l}\text { Uniportal } \\
\text { vs. } \\
\text { multiport } \\
\text { al }^{* \star *}\end{array}$ \\
\hline $\begin{array}{l}\text { Wedge } \\
\text { resections/ } \\
\text { metastasectomy }\end{array}$ & 32 & $41 \%$ & $10 \%$ & 76 & $72 \%$ & $62 \%$ \\
\hline $\begin{array}{l}\text { Anatomical } \\
\text { segmentectomie } \\
\text { s }\end{array}$ & 1 & NA & NA & 31 & $76 \%$ & $8 \%$ \\
\hline Pleural effusion & 86 & $64 \%$ & $76 \%$ & 112 & $86 \%$ & $98 \%$ \\
\hline $\begin{array}{l}\text { Mediastinal } \\
\text { biopsy }\end{array}$ & 12 & $>70 \%$ & $62 \%$ & 11 & $>68 \%$ & $100 \%$ \\
\hline
\end{tabular}

\section{Technical issues}

A series of technical considerations are mandatory to carry out a safe and effective NITOS procedure. Careful preanesthetic assessment should be made in strict cooperation with the surgical team to evaluate any possible factors leading to change of the operative plan or of the anesthesiology regimen. In particular, predictive factors of difficult intubation should be carefully evaluated. Intraoperative monitoring should include EKG, pulse-oximetry, and a radial artery catheter for real-time monitoring of blood pressure and gas exchanges. Noninvasive measurement of end-tidal $\mathrm{CO}_{2}$ on exhaled breath through a nasal capnography may also be an useful mean, and may obviate the need of repeated arterial blood samples. Whenever necessary, the level of sedation should be titrated to provide just anxiolysis or a minimally depressed level of consciousness, while preserving airway patency and ability to respond purposefully to commands. Target-control infusion of propofol at subhypnotic dosage is frequently employed, also because of its antiemetic properties. Other sedatives, such midazolam, are adopted less frequently, due to the risk of psychomotor agitation and increased airway resistance. Amongst opioids, remifentanil is the preferred one because of the advantage of an ultrashort half-life. Should a deeper sedation be necessary, monitoring of the bi-spectral index by a dedicated sensor may help to avoid excess sedative administration. A bi-spectral index value ranging from 40 to 60 is suggested to achieve an acceptable level of sedation and areflexia, while allowing a physiological tidal breathing (12-20 per minute). However, it is desirable to have the patient able to respond to command at the end of the operation, when coughing and voluntary deep ventilation are required to allow lung expansion before wound closure. Should general anesthesia become necessary, the anesthesiology staff should be equipped to rapidly proceed with urgent orotracheal intubation. In some instance, there is sufficient time to place the put the patient in 
supine position after temporary wound closure and placement of an intrapleural drainage tube. Yet, in emergent situations, double-lumen intubation with the patient lying in a lateral position cannot be avoided. If this is the case, devices such fiberoptic bronchoscope or a videolaryngoscope should be promptly available to facilitate this manoeuvre and avoid any delay, which can result in catastrophic consequences.

\section{Pitfalls and Complications}

In patients undergoing NITOS, opening of the chest is immediately followed by surgical pneumothorax with partial lung collapse. This usually allows a safe insertion of videothoracoscopic instrumentation and easy surgical manipulations, without the need of lung exclusion devices and/or intrapleural $\mathrm{CO}_{2}$ insufflation. Furthermore, we have noted that even though spontaneous ventilation is maintained, the operated lung remains practically motionless, likely because of some hysteresis establishing after lung collapse [32,33]. In the vast majority of patients, surgical pneumothorax is well tolerated, and does not give raise to clinically relevant gas-exchange impairment. This is particularly true when dealing with patients with nearly normal respiratory function. Yet, In patients with diffuse lung disease, transient intraoperative hypercarbia may occur [1,5]. It is unclear whether this effect is attributable to surgical pneumothorax, reduced compensatory ventilation due to inhibitory effect of epidural analgesia, or sedative drug effect. This hypercarbia is usually mild (permissive), and practically asymptomatic in many instances. When necessary, however, it can be corrected by manual supportive ventilation via a facial mask, while the operated lung is temporarily re-expanded by placing an intrapleural tube connected to water seal. Yet, in rare instances, the hypercarbia may give rise to psychomotor agitation and even lead to a frank panic attack. Under these unfavorable circumstances, one should refrain from completing the non-intubated operation, and immediately switch to general anesthesia instead.

Adhesions might render the operation time-consuming, unpractical or completely unfeasible, so that a non-intubated procedure should be contraindicated in patients with history of pleural disease or previous ipsilateral surgeries.

Intractable cough may occur, usually as a consequence of lung manipulations leading to stretching of vagus nerve branches behind the hilum. Preventive measures include aerosolized lidocaine administration, atropine premedication, stellate ganglion blockade, and, more frequently, vagal nerve blockade by local anesthetic injection.

Some other pitfalls can be related to the anesthetic technique which is being used. Thoracic epidural anesthesia (TEA) is the most frequently adopted one, because of broad analgesic coverage of the parietal pleura which allow performing longer and more complex operations. Yet, TEA may lead to intraoperative hypotension, which should be corrected with vasopressors rather than fluid administration, in order to prevent pulmonary overload. Other possible adverse effect of TEA include impaired compensatory ventilation, bronchial constriction due to adrenergic system blockade, and reduced right ventricle adaption to increased pulmonary artery pressure [34-38], even though the relevance of these effects have not been specifically tested in the setting of non-intubated thoracic operations. TEA should also be avoided in patients with blood clotting disorders or on antiplatelet agents, due to an estimated risk of hematoma approaching $1 / 150.000$ cases. Whenever the harm-tobenefit ratio of using TEA is into discussion, alternative measures as paravertebral infusion [39], intercostal block [40], or simple local anesthetic injection at the surgical site can be considered in an individual basis.

\section{Results}

\section{Resection of Solitary Pulmonary Nodules}

NITOS may be used to perform videothoracoscopic or open wedge resection of solitary pulmonary nodules (SPN) of unknown origin [40-48]. It can be specifically indicated to wedge out peripherally located nodules $<2 \mathrm{~cm}$ in size, which can be easily detected and excised even in a partially inflated lung. To this purpose, both TEA and paravertebral block can be employed, as they can provide a thorough analgesic control of the targeted hemithorax. Intercostal blocks, with $1.5 \mathrm{ml}$ bupivacaine at each level, can also be an option [43].

Substantially, the surgical technique does not differ from the equivalent operation performed under general anesthesia. The patient is placed in a lateral decubitus, paying attention to assure a comfortable position on the operating bed. The level of analgesia is checked before performing skin incisions by means of a pin-prick and/or a warm-cold test. If necessary, additional injection of a local anesthetic can be administered at the incision site(s). The standard approach is a 3-port videothoracoscopy. It is better to perform the first access anteriorly, on the 3rd or 4th intercostal space. At this level, the intercostal space is larger than it is posteriorly, so that a 30 -degree thoracoscope may be inserted coaxially with an endoscopic grasper to allow painless lung exploration. Once the lesion is found, the other accesses can be performed accordingly to its location. The lung lesion is then grasped, and resected by means of an endoscopic stapler. An improvement of the standard techniques has been proposed by Tseng and coworkers, who employed a dedicated "needlescopic" instrumentation through 3-mm skin incisions [44]. Lesser et al. used a two-access method with 2 and 11-mm openings and the use of a laser device to excise the nodules [46]. Alternatively, the operation may be carried out through a single, 3 to $5 \mathrm{~cm}$ incision (uniportal), through which all the endoscopic instrumentation is inserted coaxially with the thoracoscope [47]. We are also now starting to adopt this approach, which provides the twofold advantage of a lesser invasiveness and the possibility of some manual palpation of the nodule(s) to be removed. The main pitfall of this technique, however, is that it can translate in more difficult and time-consuming surgical manipulations due to instrument conflict. Thus, in our opinion, uniportal NITOS operations should be undertaken only after having achieved adequate familiarity with equivalent procedures performed in anesthesized patients.

In our institution, we have performed more than 70 NITOS resections of SNPs, either with a standard or an uniportal approach. This policy allowed us to achieve a significant reduction in postoperative hospital stay ( 3 vs. 4 days) and in the average perioperative nursing workload (2.5 vs. 4 calls per patient/day) [41]. Also, we noted a trend to better postoperative oxygenation, and higher satisfaction score in patients treated this way. Further investigations, however, are needed to reinforce these preliminary findings, and to test the hypothesis of a reduced perioperative morbidity in the subgroup of high-risk patients.

\section{Non-small cell lung cancer}

In recent years, NITOS has emerged as an intriguing treatment option for the management of patients with stage I and II non-small 
cell lung cancer. The most common indication is to perform wide wedge resections of early, peripherally located cancers in marginal surgical candidates, who are expected to benefit at most from an atraumatic surgical excision. The surgical technique is the same as for SNP removal of any origin. However, a particular attention should be paid to provide an adequately large tumor-free margin. Indeed, recent papers have shown that a $>10-\mathrm{mm}$ free-margin distance, or a distance which is equal to the tumor size, is associated with a significantly lower chance of local recurrences [49,50]. This goal is easily achieved in patients with peripheral nodule measuring less than $1 \mathrm{~cm}$ in diameter, in whom sublobar resections has been shown to provide non-inferior results compared to larger excisions [51]. However, in patients operated under spontaneous ventilation, obtaining an adequate tumor-free margin can be somewhat more difficult for lesions of larger size. In this regard, an useful trick is to grasp the nodule at its deeper pole by means of an endoscopic Satinsky forceps. A wider anterior videothoracoscopic access can also help this manouvre, as it allows the surgeon to detect the tumor boundaries by direct manual palpation. The endoscopic stapler can be then placed below the forceps, thus assuring an adequate amount of cut margin. We have treated in this way a small series of patients with an average Charlson comorbidity index of 5, achieving a 3 -years survival rate of $72 \%$. This figure seems not to be inferior to that reported with non-surgical ablative methods such as radiofrequency ablation and radiostereotaxis [41].

In general, wedge resection should be deemed as a less-than-ideal operation for NSCLC, and, at the present time, it should not replace anatomical excision in the vast majority of cases. However, some studies have suggested that, in peripherally-located tumors measuring $1 \mathrm{~cm}$ or less, wedge resections can be as effective as larger surgeries in terms of long-term survival chance [50-52]. It should be noted that these early cancers are expected to become increasingly detected thanks to the establishment of public health screening programs. For this reason, NITOS should be also viewed under the light of possible future development of tailored treatment protocols, which are expected to integrate tissue-sparing operations with molecular targeted therapies and monoclonal antibodies.

The use of NITOS to carry out videothoracoscopic anatomical lung resection for NSCLC is much more recent [43,53-55], even though occasional reports of major surgeries performed with regional anesthesia alone can be found in the historical surgical literature [56-58]. The National Taiwan University group must be credited for the introduction and development of this pioneering thoracic surgery field. The first report in this regard dates back to 2010, when Chen et al first reported on a preliminary series of 30 patients undergoing NITOS lobectomy [43]. Despite the limited study size, these authors found a clear trend toward a lower postoperative morbidity rate this group, when compared to matched patients receiving the same operations under general anesthesia. Since then, the number of performed procedures has remarkably increased. The last updates from the same group report more than 200 procedures to have been performed, even including 28 anatomical segmentectomies [43]. Despite the safety of merging videothoracoscopic approach with nonintubated anesthesia could be put into discussion, the authors have reported quite encouraging results in this regard. Indeed, the need of conversion to general anesthesia was well below $10 \%$, and basically attributable to mediastinal movements, refractory hypoxia, and adhesions. More importantly, bleeding requiring urgent thoracotomy occurred in one patient only. These figures have been substantially reproduced by our group in a smaller series of 32 patients undergoing NITOS segmentectomies [58]. Oncology appropriateness seems also reliably achievable, as Cheng and coworkers reported no substantial difference as far as mediastinal lymph-node sampling was concerned [43]. Other limitations of NITOS to perform major lung resections are, however, to be discussed. Obviously, this surgical modality requires highest technical skills and familiarity with videothoracoscopic lung resections. It is also unclear whether to as the expected benefit in terms of postoperative morbidity can be reproduced in diverse patient's subcategories and risk classes. Finally, long-term results are not available yet, so that definitive conclusions in terms of overall survival and recurrence rates cannot be drawn at the present time.

\section{Pulmonary metastasectomy}

NITOS can be considered to perform videothoracoscopic removal of pulmonary metastases $[41,59,60]$. The ideal candidate is a patient with few (3 or less), easy-to-remove lung lesions, or a patient in whom excision of a single metastatic lesion is indicated for diagnostic purpose without the goal of complete resection. We have employed NITOS to treat a small series of patients with such features. When performing a matched comparison with patients undergoing standard videothoracoscopic metastasectomy, we found a significant reduction in global operative time (62 vs. 147 minutes, $p<0.001$, and in hospital stay ( 2.5 vs 4 days, $\mathrm{p}=0.02$ ). Medium-term recurrences were similar between groups.

The main limitation of videothoracoscopy in the setting of pulmonary metastasecomy applies to NITOS as well, and consists in the difficulty to palpate the lung in search of radiologically-occult lesions, which may be found in more than $10 \%$ of patients. In the past, we used to employ a so-called substernal, hand-assisted thoracoscopic approach to overcome this problem. More recently, we tend to prefer a uniportal NITOS approach via a $5 \mathrm{~cm}$ anterior access. This approach allows an easy manual palpation of the targeted lung, which is also helped by partial inflation, with a quite reduced surgical traumatism. Uniportal NITOS may also replace a substernal approach to perform simultaneous bilateral operations, whenever the latter cannot be safely performed [61]. This may be the case of patients who had received previous median laparotomy to treat colorectal cancer, who are often referred to thoracic surgeons for pulmonary metastases. Patients with metastases from laryngeal cancer may also easily approach via NITOS, as permanent tracheostomy allows a rapid and safe control of the major airway should intubation become necessary.

Main contraindications to NITOS in this setting are redo metastasectomies, and previous ipsilateral radiotherapy, which could have been performed in breast cancer patients. One should also carefully investigate on the occurrence of pleural effusion which could have occurred at the time of the surgery for primary cancer removal. This complication, which may result in unmanageable pleural adhesions, may be frequently overlooked or completely forgotten by patients, especially if the perioperative recovery had been affected by more severe or troublesome conditions. Finally, the value of pulmonary metastasectomies in itself should be discussed, regardless of the adopted surgical modality. Indeed, despite many investigators have reported survival rates as high as $50 \%$, the practice of metastasectomy is mostly based on observational studies or retrospective case series. We expect that the results of the dedicated randomized controlled trial currently underway in Europe will soon help shed new light on the management of this complex disease. The possible role of different anesthetic regimen on overall results of pulmonary metastasectomies, and their potential interaction with cancer progression, should also be addressed in future research. 


\section{Malignant pleural effusion}

Patients planned for minimally-invasive management of malignant pleural effusion often present deteriorated clinical condition. Therefore, they are expected to benefit at most by avoidance of general anesthesia and OLV, which also appear to be disproportionate against the relatively simplicity of the procedure [45,61-63].

NITOS operation in these instances usually consists in aspiration of the effusion, pleural biopsy, and possibly pleurodesis in order to prevent recurrences. The patient can remain completely awake during the procedure, although twilight sedation may be needed in some instances. Different drug regimens can be used to this purpose, without any obvious advantage of one versus the others. The procedure can be usually performed with one small thoracoscopic access, with just local injection of anesthetic agents at the site of surgical opening. The opening of previously inserted chest drainage may be used as well, unless there is no sign of infection. Ten milliliters of a mixture containing $2 \%$ lidocaine and $7.5 \%$ ropivacaine is sufficient to provide a rapid and durable analgesic effect, so that it can cover the entire procedure. Additional injection(s) can be performed at the site(s) of pleural biopsy. A $20-\mathrm{mm}$ flexible trocar should be preferred to allow insertion of a 30-degrees thoracoscope alongside with the other other operative instruments. Drainage of the pleural fluid is performed gradually, while the ability of the lung to expand is repeatedly checked by asking the patient to breathe deeply. Whenever lung expansion is deemed adequate, chemical pleurodesis can be indicated. To this purpose, we prefer use talc as the elective pleurodesic agent, due to its proven efficacy, and possible inhibition of tumor growth via an anti-angiogenetic effect [64]. Use of the largeparticled $(5-70 \mu \mathrm{m})$ talc powder has been shown to obviate the risk of serious postoperative complications such as acute-lung injury or pulmonary edema $[62,65]$. One should remind that talc insufflation within the pleural cavity may provoke pain in fully alert patients. Short-acting local anesthetics can be sprayed intrapleurally before proceeding with pleurodesis, and additional sedation may be given at this point.

Reported success rates for videothoracoscopic talc pleurodesis range from $84 \%$ to $95 \%$ [66-72]. These figures appear to be remarkably higher that those observed after bedside instillation of talc $[68,70]$ or other agents $[63,79]$. We have evaluated comparatively the results obtained in a large series of patients with malignant pleural effusion, who were treated by either standard videothoracoscopy or NITOS. The latter resulted in a shorter duration of hospital stay $(\mathrm{p}<0.014)$, in a lesser perioperative complication rate $(5.2 \%$ vs. $9 \%, \mathrm{p}=0.042)$, and in reduced costs, with a mean saving of 3000 Eurodollars a patients [2]. Furthermore, NITOS seems to achieve better results in terms of early postoperative quality of life [71], and did not show inferior efficacy in achieving and effective pleurodesis. All these findings highlights that NITOS could be a reliable means to take the advantage of a videothoracoscopic procedure, while avoiding the risks related to general anesthesia in these fragile patients. Controversial results have been, however, reported by Debeljak et al. [72], who found a higher perioperative side-effect rate of videothoracoscopic pleurodesis under local anesthesia when compared with talc slurry (73\% vs. $41 \%)$, and no superior efficacy.

When dealing with patients unfit for any surgical procedure, regardless of the type of aneshtesia, placement of an indwelling, tunneled intrapleural catether (PleurX, Carefusion, USA) can be an option $[73,74]$. The latter device provides the advantages of a very short hospitalization, a simple insertion technique, and an easy home management. The PleurX catheter may be also be used at the end of a NITOS operation, whenever talc pleurodesis is not indicated because of unsatisfactory lung reexpansion. Potential pitfalls may include blockage, infection, and failure to achieve definitive pleural obliteration. Also, due to need for repeated home nursing assistance and outpatient visits, cost-effectiveness is reached only when restricting the use in patients with very short ( $<6$ months) lifeexpectancy [74].

\section{Mediastinal masses}

Patients with huge mediastinal masses are more susceptible of serious anesthesia-related complications, including airway obstruction, bronchospasm, hypotension, and reflex arrhythmias $[75,76]$. In these patients, surgery can be required in order to expeditiously obtain a diagnostic sample and thus proceed with a lifesaving treatment. Under these circumstances, NITOS operation may represent an useful option, even though its harm-to-benefit ratio versus non-surgical diagnostic methods should be carefully evaluated. The surgical route varies according to the localization of the lesion. Anterior mediastinal masses are well manageable by either nonintubated mediastinotomy [77,78] or videothoracoscopy [41]. The latter should be preferred whenever associated conditions possibly require videothoracoscopic management do exist [41]. These may include pleural or pericardial effusion, chylothorax, and associated pulmonary lesions of uncertain origin. The videothoracoscopic technique does not differ substantially from the same procedure performed under general anesthesia. A 45-degree flank position allows an easy videothoracoscopic approach to anterior mediastinum, and will facilitate switching to supine decubitus should emergent intubation become necessary. A single access at the 4th intercostal space is sufficient in many instances. One must remind that surgical manipulations of the inflamed mediastinal pleura can be painful, so that local anesthetics can be sprayed over this area before proceeding with biopsy. In our experience, we have treated this way a total of 23 patients with diverse mediastinal malignancies, reaching a $100 \%$ diagnostic yield with neither intra- or perioperative complication, nor need for switching to general anesthesia for any reason. All these patients had a various degree of superior vena cava compression or other associated signs including stridor and resting dyspnea. In 2 instances, NITOS allowed us to treat an associated, symptomatic pericardial effusion by means of a "window" technique.

One of the main concerns of NITOS in this setting, however, is the issue of airway control in case of unexpected surgical complications or sudden intraoperative asphyxia. The latter complication is significantly higher in patient with tracheal compression $>50 \%$ (figure 2 ), and may be triggered by airway edema, surgical manipulations, and gravity compression from a gross paratracheal mass during lateral decubitus. In these instances, the surgical theater should be staffed and equipped to perform urgent rigid bronchoscopy, which may result a life-saving manouvre. Some authors even recommend being prepared to perform emergent extracorporeal circulation [76]. If the clinical situation portrays an elevated risk in this regard, a valid compromise solution could be to proceed with orotracheal intubation in the awake patient, and administer them sedatives while avoiding respiratory depression. The alpha-2 agonist dexmedetomidine can be particularly useful to this purpose, since it can provide light to deep sedation level without preventing spontaneous ventilation [79]. 


\section{MACTS for thymoma and myasthenia gravis}

Matsumoto has proposed NITOS thymectomy [80], performed via either median sternotomy or a videothoracoscopic technique, to treat myasthenia gravis, either associated or not with thymoma. The basic idea was to obviate the need of myorelaxants, which can be responsible for severe respiratory impariment in these patients. The operation was offered to patients with Myasthenia Gravis Foundation of America grade I-II patients, and having capsulated thymomas of less than $3 \mathrm{~cm}$ in size. The feasibility was excellent, and no relevant complication occurred in more than 30 treated patients.

\section{Conclusions}

In recent years, NITOS is being increasingly considered as an effective tool in the armamentarium of modern era thoracic surgeons. Even though there is no current level-A evidence to support or reject this practice, we are confident that future research, founded on a cooperative and constructive interaction between international centers, will soon provide a more robust knowledge to better define its advantages and limitations. Meanwhile, it would be desirable NITOS to be seen under a multidisciplinary light, rather than being merely considered as an ancillary surgical option. It is hopeful that thoracic surgeons will work in strict cooperation with anesthesiologists, oncologists, interventional radiologists, chest physicians, and specialized nurses to optimize at most the the decision-making process, as well as to design and conduct appropriate clinical trials on this topic. We also suggest that an appropriate training on NITOS should be awarded institutionally, and that the proficiency with this kind of surgery should be cerfied, rather than reported in a selfreferentiality basis, to be listed as an extra credential when submitting application for surgical positions. For this reason, we have established an educational program, which has been approved by the research ethics board of our academic institution [2,3]. This program is founded on active participation of surgical residents and anesthesiologists to the NITOS sessions, with commitment to maintain the same team for at least 40 consecutive procedures a year. Lecture series, as well as educational tool as dry and wet labs and operating room simulations are also a part of our dedicated training. We are confident that such a policy will help increase at most the proficiency of our attending surgeons with NITOS procedures, and will ultimately help popularize the benefits of this practice amongst physicians and patients.

\section{References}

1. Kao MC, Lan CH, Huang CJ (2012) Anesthesia for awake video-assisted thoracic surgery. Acta Anaesthesiol Taiwan 50: 126-130.

2. Mineo TC, Ambrogi V (2012) Efficacy of awake thoracic surgery. J Thorac Cardiovasc Surg 143: 249-250.

3. Mineo TC (2007) Epidural anesthesia in awake thoracic surgery. Eur J Cardiothorac Surg 32: 13-19.

4. Mineo TC, Ambrogi V (2012) Awake thoracic surgery for secondary spontaneous pneumothorax: another advancement. J Thorac Cardiovasc Surg 144: 1533-1534.

5. Dong Q, Liang L, Li Y, Liu J, Yin W, et al. (2012) Anesthesia with nontracheal intubation in thoracic surgery. J Thorac Dis 4: 126-130.

6. Schilling T, Kozian A, Huth C, Bühling F, Kretzschmar M, et al. (2005) The pulmonary immune effects of mechanical ventilation in patients undergoing thoracic surgery. Anesth Analg 101: 957-965, table of contents.
7. Herndon B, Yagan M, Reisz G, Ireland JC (2008) Metabolic and biochemical responses of the healthy human lung to nonthoracic surgery. Lung 186: 63-70

8. Pinheiro de Oliveira R, Hetzel MP, dos Anjos Silva M, Dallegrave D, Friedman G (2010) Mechanical ventilation with high tidal volume induces inflammation in patients without lung disease. Crit Care 14: R39.

9. Zupancich E, Paparella D, Turani F, Munch C, Rossi A, et al (2005). Mechanical ventilation affects inflammatory mediators in patients undergoing cardiopulmonary bypass for cardiac surgery: a randomized clinical trial. J Thorac Cardiovasc Surg 130:378-383.

10. Wolthuis EK, Choi G, Dessing MC, Bresser P, Lutter R, et al. (2008) Mechanical ventilation with lower tidal volumes and positive endexpiratory pressure prevents pulmonary inflammation in patients without preexisting lung injury. Anesthesiology 108: 46-54.

11. Pavone LA, Albert S, Carney D, Gatto LA, Halter JM, et al. (2007) Injurious mechanical ventilation in the normal lung causes a progressive pathologic change in dynamic alveolar mechanics. Crit Care 11: R64.

12. Sugasawa Y, Yamaguchi K, Kumakura S, Murakami T, Kugimiya T, et al. (2011) The effect of one-lung ventilation upon pulmonary inflammatory responses during lung resection. J Anesth 25: 170-177.

13. Funakoshi T, Ishibe $\mathrm{Y}$, Okazaki N, Miura K, Liu R, et al. (2004) Effect of re-expansion after short-period lung collapse on pulmonary capillary permeability and pro-inflammatory cytokine gene expression in isolated rabbit lungs. Br J Anaesth 92: 558-563.

14. Kozian A, Schilling T, Röcken C, Breitling C, Hachenberg T, et al. (2010) Increased alveolar damage after mechanical ventilation in a porcine model of thoracic surgery. J Cardiothorac Vasc Anesth 24: 617-623.

15. Yin K, Gribbin E, Emanuel S, Orndorff R, Walker J, et al. (2007) Histochemical alterations in one lung ventilation. J Surg Res 137: 16-20.

16. Misthos P, Katsaragakis S, Milingos N, Kakaris S, Sepsas E, et al. (2005) Postresectional pulmonary oxidative stress in lung cancer patients. The role of one-lung ventilation. Eur J Cardiothorac Surg 27: 379-382.

17. Licker M, Fauconnet P, Villiger Y, Tschopp JM (2009) Acute lung injury and outcomes after thoracic surgery. Curr Opin Anaesthesiol 22: 61-67.

18. Licker M, de Perrot M, Spiliopoulos A, Robert J, Diaper J, et al. (2003) Risk factors for acute lung injury after thoracic surgery for lung cancer. Anesth Analg 97: 1558-1565.

19. Tekinbas C, Ulusoy H, Yulug E, Erol MM, Alver A, et al. (2007) Onelung ventilation: for how long? J Thorac Cardiovasc Surg 134: 405-410.

20. Cheng YJ, Chan KC, Chien CT, Sun WZ, Lin CJ (2006) Oxidative stress during 1-lung ventilation. J Thorac Cardiovasc Surg 132: 513-518.

21. Cobelens PM, van Putte BP, Kavelaars A, Heijnen CJ, Kesecioglu J (2009) Inflammatory consequences of lung ischemia-reperfusion injury and low-pressure ventilation. J Surg Res 153: 295-301.

22. Leite CF, Calixto MC, Toro IF, Antunes E, Mussi RK (2012) Characterization of pulmonary and systemic inflammatory responses produced by lung re-expansion after one-lung ventilation. J Cardiothorac Vasc Anesth 26: 427-432.

23. YuluÄŸ E, Tekinbas C, Ulusoy H, Alver A, Yenilmez E, et al. (2007) The effects of oxidative stress on the liver and ileum in rats caused by onelung ventilation. J Surg Res 139: 253-260.

24. Tønnesen E, Höhndorf K, Lerbjerg G, Christensen NJ, Hüttel MS, et al. (1993) Immunological and hormonal responses to lung surgery during one-lung ventilation. Eur J Anaesthesiol 10: 189-195.

25. Misthos P, Katsaragakis S, Theodorou D, Milingos N, Skottis I (2006) The degree of oxidative stress is associated with major adverse effects after lung resection: a prospective study. Eur J Cardiothorac Surg 29: 591-595.

26. Miñambres E, Burón J, Ballesteros MA, Llorca J, Muñoz P, et al. (2009) Tracheal rupture after endotracheal intubation: a literature systematic review. Eur J Cardiothorac Surg 35: 1056-1062.

27. Gottschalk A1, Sharma S, Ford J, Durieux ME, Tiouririne M (2010) Review article: the role of the perioperative period in recurrence after cancer surgery. Anesth Analg 110: 1636-1643. 
28. Tavare AN, Perry NJ, Benzonana LL, Takata M, Ma D (2012) Cancer recurrence after surgery: direct and indirect effects of anesthetic agents. Int J Cancer 130: 1237-1250.

29. Vázquez SM, Mladovan AG, Pérez C, Bruzzone A, Baldi A, et al. (2006) Human breast cell lines exhibit functional alpha2-adrenoceptors. Cancer Chemother Pharmacol 58: 50-61.

30. Vanni G, Tacconi F, Sellitri F, Ambrogi V, Mineo TC, et al. (2010) Impact of awake videothoracoscopic surgery on postoperative lymphocyte responses. Ann Thorac Surg 90: 973-978.

31. Tacconi F, Pompeo E, Sellitri F, Mineo TC (2010) Surgical stress hormones response is reduced after awake videothoracoscopy. Interact Cardiovasc Thorac Surg 10: 666-671.

32. Rimensberger PC, Cox PN, Frndova H, Bryan AC (1999) The open lung during small tidal volume ventilation: concepts of recruitment and "optimal" positive end-expiratory pressure. Crit Care Med 27: 1946-1952.

33. Axe JR, Abbrecht PH (1985) Analysis of the pressure-volume relationship of excised lungs. Ann Biomed Eng 13: 101-117.

34. Kochi T, Sako S, Nishino T, Mizuguchi T (1989) Effect of high thoracic extradural anaesthesia on ventilatory response to hypercapnia in normal volunteers. Br J Anaesth 62: 362-367.

35. Warner DO, Warner MA, Ritman EL (1996) Human chest wall function during epidural anesthesia. Anesthesiology 85: 761-773.

36. Groeben $\mathrm{H}$ (2006) Epidural anesthesia and pulmonary function. J Anesth 20: 290-299.

37. Groeben H (2000) Effects of high thoracic epidural anesthesia and local anesthetics on bronchial hyperreactivity. J Clin Monit Comput 16: 457-463.

38. Horlocker TT (2011) Complications of regional anesthesia and acute pain management. Anesthesiol Clin 29: 257-278.

39. Piccioni F, Langer M, Fumagalli L, Haeusler E, Conti B, et al. (2010) Thoracic paravertebral anaesthesia for awake video-assisted thoracoscopic surgery daily. Anaesthesia 65: 1221-1224.

40. Chen KC, Cheng YJ, Hung MH, Tseng YD, Chen JS (2012) Nonintubated thoracoscopic lung resection: a 3-year experience with 285 cases in a single institution. J Thorac Dis 4: 347-351.

41. Mineo TC, Tacconi F. From "awake" to "monitored anesthesia care" thoracic surgery: a 15 year evolution (2014). Thorac Cancer 2014; 5:1-13.

42. Klijian A, Andonian N (2013). Awake video assisted thoracic surgery series report. J Cardiothorac Surg 8: 243

43. Chen KC, Cheng YJ2, Hung MH2, Tseng YD3, Chen JS1 (2014) Nonintubated thoracoscopic surgery using regional anesthesia and vagal block and targeted sedation. J Thorac Dis 6: 31-36.

44. Tseng YD, Cheng YJ, Hung MH, Chen KC, Chen JS (2012) Nonintubated needlescopic video-assisted thoracic surgery for management of peripheral lung nodules. Ann Thorac Surg 93: 1049-1054.

45. Katlic MR, Facktor MA (2010) Video-assisted thoracic surgery utilizing local anesthesia and sedation: 384 consecutive cases. Ann Thorac Surg 90: 240-245.

46. Lesser TG (2012) Laser application enables awake thoracoscopic resection of pulmonary nodules with minimal access. Surg Endosc 26 1181-1186.

47. Rocco G, Romano V, Accardo R, Tempesta A, La Manna C, et al (2010) Awake single-access (uniportal) video-assisted thoracoscopic surgery for peripheral pulmonary nodules in a complete ambulatory setting. Ann Thorac Surg 89:1625-1627.

48. Mohiuddin K, Haneuse S2, Sofer T2, Gill R3, Jaklitsch MT1, et al. (2014) Relationship between margin distance and local recurrence among patients undergoing wedge resection for small $\left(\hat{\mathrm{a}} \%{ }_{0} \mathrm{a} 2 \mathrm{~cm}\right)$ non-small cell lung cancer. J Thorac Cardiovasc Surg 147: 1169-1177.

49. Sawabata N, Maeda H, Matsumura A, Ohta M, Okumura M; Thoracic Surgery Study Group of Osaka University (2012) Clinical implications of the margin cytology findings and margin/tumor size ratio in patients who underwent pulmonary excision for peripheral non-small cell lung cancer. Surg Today 42: 238-244.
50. Hamatake D, Yoshida Y, Miyahara S, Yamashita S, Shiraishi T, et al. (2012) Surgical outcomes of lung cancer measuring less than $1 \mathrm{~cm}$ in diameter. Interact Cardiovasc Thorac Surg 15: 854-858.

51. Chamogeorgakis T, Ieromonachos C, Georgiannakis E, Mallios D (2009). Does lobectomy achieve better survival and recurrence rates than limited pulmonary resection for T1N0M0 non-small cell lung cancer patients? Interact Cardiovasc Thorac Surg 8:364-372.

52. Wu CY, Chen JS, Lin YS, Tsai TM, Hung MH, et al. (2013) Feasibility and safety of nonintubated thoracoscopic lobectomy for geriatric lung cancer patients. Ann Thorac Surg 95: 405-411.

53. Al-Abdullatief M, Wahood A, Al-Shirawi N, Arabi Y, Wahba M, et al. (2007) Awake anaesthesia for major thoracic surgical procedures: an observational study. Eur J Cardiothorac Surg 32: 346-350.

54. Shao W, Wang W, Yin W, Guo Z, Peng G, et al. (2013) Nonintubated thoracoscopic lobectomy plus lymph node dissection following segmentectomy for central type pulmonary masses. Chin J Cancer Res 25: 124-127.

55. VISCHNEVSKI AA (1954) [Local anesthesia in thoracic surgery: lungs, heart and esophagus]. Minerva Anestesiol 20: 432-435.

56. OSSIPOV BK (1960) Local anesthesia in thoracic surgery: 20 years experience with 3265 cases. Anesth Analg 39: 327-332.

57. Buckingham WW, Beatty AJ, Brasher CA, Ottosen P (2009). The technique of administering epidural anesthesia in thoracic surgery. 1950. Chest 136:e30.

58. Mineo TC, Tacconi F, Ambrogi V, Sellitri F (2014). Non-intubated thoracic surgery segmentectomy: when and for who? Ann Thorac Surg [In Press].

59. Mineo TC (2008) Thoracoscopic approach to lung metastases. Minerva Chir 63: 511-516.

60. Tacconi F, Ambrogi V, Pompeo E, Sellitri F, Mineo TC (2002). Substernal hand-assisted videothoracoscopic lung metastasectomy: longterm results in a selected patient cohort. Thorac Cancer 2:45-53.

61. Rahman NM, Ali NJ, Brown G, Chapman SJ, Davies RJ, et al. (2010) Local anaesthetic thoracoscopy: British Thoracic Society Pleural Disease Guideline 2010. Thorax 65 Suppl 2: ii54-60.

62. Griffo S, Gravino E, Luciano A, Ferrante G (2005) The treatment by V.A.T.S. and M.A.C. of secondary neoplastic pleural effusion in the old patient (> 70 years). Acta Biomed 76 Suppl 1: 72-75.

63. Roberts ME, Neville E, Berrisford RG, Antunes G, Ali NJ; BTS Pleural Disease Guideline Group (2010) Management of a malignant pleural effusion: British Thoracic Society Pleural Disease Guideline 2010. Thorax 65 Suppl 2: ii32-40.

64. Nasreen N, Mohammed KA, Brown S, Su Y, Sriram PS, et al. (2007) Talc mediates angiostasis in malignant pleural effusions via endostatin induction. Eur Respir J 29: 761-769.

65. Hartman DL, Gaither JM, Kesler KA, Mylet DM, Brown JW, et al (1993). Comparison of insufflated talc under thoracoscopic guidance with standard tetracycline and bleomycin pleurodesis for control of malignant pleural effusion. J Thorac Cardiovasc Surg 105:743-747.

66. Danby CA, Adebonojo SA, Moritz DM (1998) Video-assisted talc pleurodesis for malignant pleural effusions utilizing local anesthesia and I.V. sedation. Chest 113: 739-742.

67. Kolschmann S, Ballin A, Gillissen A (2005) Clinical efficacy and safety of thoracoscopic talc pleurodesis in malignant pleural effusions. Chest 128: 1431-1435.

68. Stefani A, Natali P, Casali C, Morandi U (2006) Talc poudrage versus talc slurry in the treatment of malignant pleural effusion. A prospective comparative study. Eur J Cardiothorac Surg 30: 827-832.

69. Diacon AH, Wyser C, Bolliger CT, Tamm M, Pless M, et al (2000). Prospective randomized comparison of thoracoscopic talc poudrage under local anesthesia versus bleomycin instillation for pleurodesis in malignant pleural effusion. Am J Respir Crit Care Med 162:1445-1449.

70. Dresler CM, Olak J, Herndon JE 2nd, Richards WG, Scalzetti E, et al. (2005) Phase III intergroup study of talc poudrage vs talc slurry sclerosis for malignant pleural effusion. Chest 127: 909-915. 
Citation: Mineo TC and Tacconi F. Nonintubated Videothoracoscopic Operations in Thoracic Oncology. Journal of Surgery [Jurnalul de Chirurgie] 2014; 10(1): 25-33. doi:10.7438/1584-9341-10-1- 6

Page 33

71. Mineo TC, Sellitri F, Tacconi F, Ambrogi V (2014). Quality of life and outcomes after non-intubated vs intubated video-thoracoscopic pleurodesis for malignant pleural effusion: comparison by a casematched study. J Pall Med [In Press].

72. Debeljak A, Kecelj P, Triller N, Letonja S, Kern I, et al. (2006) Talc pleurodesis: comparison of talc slurry instillation with thoracoscopic talc insufflation for malignant pleural effusions. J BUON 11: 463-467.

73. Sioris T, Sihvo E, Salo J, Räsänen J, Knuuttila A (2009) Long-term indwelling pleural catheter (PleurX) for malignant pleural effusion unsuitable for talc pleurodesis. Eur J Surg Oncol 35: 546-551.

74. Olden AM, Holloway R (2010) Treatment of malignant pleural effusion: PleuRx catheter or talc pleurodesis? A cost-effectiveness analysis. J Palliat Med 13: 59-65.

75. Gothard JW (2008) Anesthetic considerations for patients with anterior mediastinal masses. Anesthesiol Clin 26: 305-314.
76. Goh MH, Liu XY, Goh YS (1999) Anterior mediastinal masses: an anaesthetic challenge. Anaesthesia 54: 670-674.

77. Mahmodlou R, Mohtazeri V, Rahimi-Rad MH, Sekoti M (2011) Minimediastinotomy under local anesthesia for biopsy of anterior mediastinal masses with airway compression. Pneumologia 60: 143-146.

78. Rendina EA, Venuta F, De Giacomo T, Ciccone AM, Moretti MS, et al (2002) Biopsy of anterior mediastinal masses under local anesthesia. Ann Thorac Surg 74: 1720-1722.

79. Abdelmalak B, Marcanthony N, Abdelmalak J, Machuzak MS, Gildea TR, et al. (2010) Dexmedetomidine for anesthetic management of anterior mediastinal mass. J Anesth 24: 607-610.

80. Matsumoto I, Oda M, Watanabe G (2008) Awake endoscopic thymectomy via an infrasternal approach using sternal lifting. Thorac Cardiovasc Surg 56: 311-313. 